\title{
Toppled television sets and head injuries in the pediatric population: a framework for prevention
}

\author{
Michael D. Cusimano, MD, MHPE, FRCS, PhD, ${ }^{1,2}$ and Nadine Parker, MSc, BSc ${ }^{2}$ \\ ${ }^{1}$ Division of Neurosurgery, Department of Surgery, St. Michael's Hospital, and Dalla Lhana School of Public Health, University \\ of Toronto; and 'Injury Prevention Research Office, Li Ka Shing Knowledge Institute, Keenan Research Centre, St. Michael's \\ Hospital, Toronto, Ontario, Canada
}

Injuries to children caused by falling televisions have become more frequent during the last decade. These injuries can be severe and even fatal and are likely to become even more common in the future as TVs increase in size and become more affordable.

To formulate guidelines for the prevention of these injuries, the authors systematically reviewed the literature on injuries related to toppling televisions. The authors searched MEDLINE, PubMed, Embase, Scopus, CINAHL (Cumulative Index to Nursing and Allied Health Literature), Cochrane Library, and Google Scholar according to the Cochrane guidelines for all studies involving children 0-18 years of age who were injured by toppled TVs. Factors contributing to injury were categorized using Haddon's Matrix, and the public health approach was used as a framework for developing strategies to prevent these injuries.

The vast majority (84\%) of the injuries occurred in homes and more than three-fourths were unwitnessed by adult caregivers. The TVs were most commonly large and elevated off the ground. Dressers and other furniture not designed to support TVs were commonly involved in the TV-toppling incident. The case fatality rate varies widely, but almost all deaths reported (96\%) were due to brain injuries. Toddlers between the ages of 1 and 3 years most frequently suffer injuries to the head and neck, and they are most likely to suffer severe injuries. Many of these injuries require brain imaging and neurosurgical intervention. Prevention of these injuries will require changes in TV design and legislation as well as increases in public education and awareness. Television-toppling injuries can be easily prevented; however, the rates of injury do not reflect a sufficient level of awareness, nor do they reflect an acceptable effort from an injury prevention perspective.

http://thejns.org/doi/abs/10.3171/2015.2.PEDS14472

KEY WORDS television toppling; pediatrics; head injury; traumatic brain injury; review; systematic review; trauma

$\mathrm{T}$ ELEVISIONS can be dangerous to children and especially to toddlers between the ages of 1 and 3 years..$^{15}$ These devices are present in $99 \%$ of American and 95\% of Canadian homes and have become larger over time. ${ }^{33,34}$ Newer televisions, such as wide-screen plasma TVs, are heavy and are often not well fixed to a stable base. A typical 36-inch-wide TV falling just $1 \mathrm{~m}$ creates the momentum equivalent to a 1-year-old child weighing $10 \mathrm{~kg}$ falling from 10 stories. ${ }^{4}$ Small children injured by falling TVs usually suffer head and neck injuries such as fractures and intracranial hemorrhages, which can be fatal. ${ }^{4,38,54}$ Such injuries are not rare events in developed countries where TVs are commonplace: TV toppling is ranked third in the top 5 hidden home hazards in the US, ${ }^{8,37}$ and the US Consumer Product Safety Commission (CPSC) reported 19,200 injuries between 2008 and 2010, up from 16,500 from 2006 to $2008 .^{18,19}$ Over the last decade TV-related injuries have become more common, a trend that is likely to continue as TVs increase in size and more households globally are able to afford a $\mathrm{TV}^{33,35,42,47}$

Although literature exists on injuries related to the

ABBREVIATIONS ASTM = American Society for Testing Materials; CPSC = Consumer Product Safety Commission; CRT = cathode ray tube; FPTV = flat-panel television; $\mathrm{PHA}=$ public health approach; UK = United Kingdom; UL = Underwriters Laboratory. ACCOMPANYING EDITORIAL See pp 1-2. DOI: 10.3171/2015.2.PEDS1582.

SUBMITTED September 8, 2014. ACCEPTED February 4, 2015.

INCLUDE WHEN CITING Published online September 29, 2015; DOI: 10.3171/2015.2.PEDS14472. 
toppling of televisions, it is primarily epidemiological or clinical in nature, without a focus on prevention. Despite annual warnings on the US CPSC website about TV tipover and Health Canada website warnings of TV tipping accidents, the rate of injury remains high and appears to be increasing. ${ }^{9,11,12,18,19,24,25}$ The goal of this study was to systematically review the literature on injuries related to toppling TVs and to formulate a framework for the prevention of these injuries.

\section{Methods}

Using the Cochrane guidelines for systematic review, we searched Medline, PubMed, Embase, Scopus, CINAHL (Cumulative Index to Nursing and Allied Health Literature), the Cochrane Library, and Google Scholar using the following terms: "head injury," "neck injury," "cranial injury," "skull fracture," "brain injury," "cerebral contusion," "cerebral laceration," "subdural hematoma," "subarachnoid hemorrhage," "epidural hematoma," "diffuse axonal injury," "traumatic brain injury," "TBI," "crush and static head injuries," "TV," "television," "infant," "child," and "youth." We also searched the US CPSC and Health Canada websites using the same key words. Hand searches of the journals Injury Prevention, Journal of Neurosurgery: Pediatrics, and the Journal of Pediatric and Child Health were performed, starting with publications from 1988 (the initiation of the first study of injuries related to falling TVs, by DiScala et al. ${ }^{15}$ which was published in 2001) through December 28, 2014.

We included all studies involving children 0-18 years of age who were injured by toppled TVs. Studies investigating household furniture injuries including televisions as furniture were also included in the literature review. Studies with no mention of head injuries inflicted by toppled televisions were excluded. Studies with injuries inflicted by television components in the absence of a toppling event were also excluded. A combined total of 4163 article titles and abstracts were read and screened according to the aforementioned criteria. Thirty-three articles met these criteria and were selected for full manuscript review. Of those 33 articles, 29 studies met the criteria fully and were selected for inclusion in the literature review. Four articles were excluded after full manuscript review because the reported injuries were inflicted by televisions but did not result from a tipover, or they were studies using the same group of injured individuals. The diagram of the systematic search and review is found in Fig. 1.

Factors contributing to injury were categorized using Haddon's Matrix and the public health approach (PHA) as the framework for developing a strategy for the prevention of these injuries. Haddon's Matrix has a systematic setup for identifying risk factors, whereas the PHA outlines a method for developing a plan of action to prevent injuries. ${ }^{30}$ The PHA has 4 levels: surveillance, identification of risk and protective factors, implementation, and development and evaluation of interventions. The data in the Haddon's Matrix are divided into 3 phases: pre-event, event, and post-event. Columns labeled "host," "agent," and "environment" are used to organize the factors based on the injured party, the vehicle causing the injury, and the social

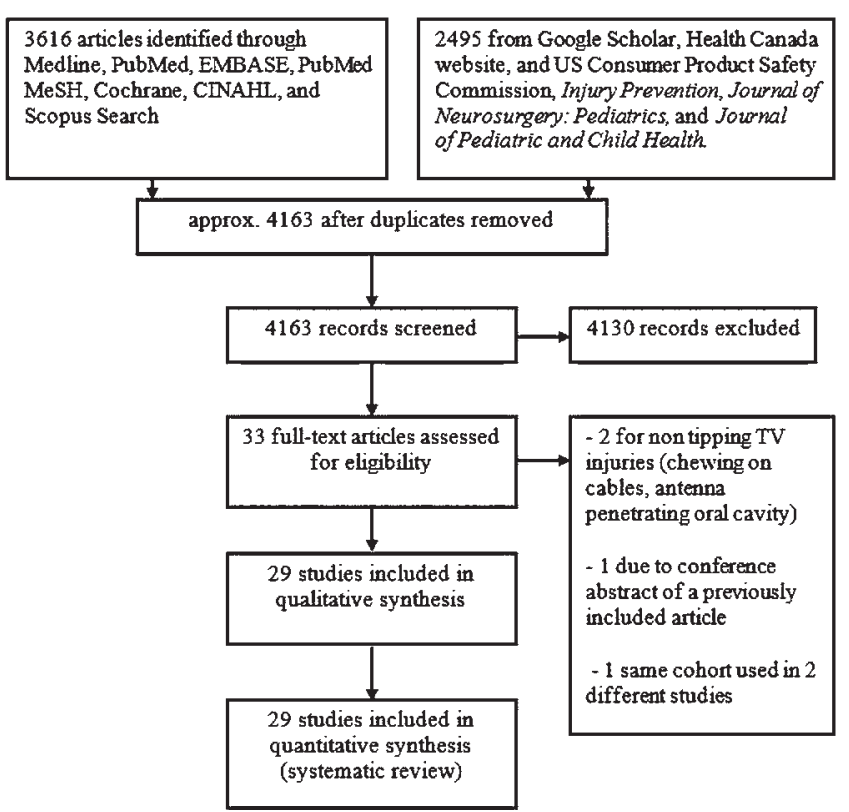

FIG. 1. Search protocol flowchart. This flowchart depicts the steps taken to systematically review the literature. Reasons for not including articles that received full manuscript review are also provided. Of 4163 articles initially found using the search terms, 29 met the criteria for inclusion in this review.

and physical situation surrounding the incident. In the case of TV-toppling injuries the hosts are children, particularly toddlers (children between the ages of 1 and 3 years); the agent is the television set; and the environment includes both the physical surroundings, such as the TV support furniture, and the social environment, such as caregiver supervision. From the factors presented in Haddon's Matrix and the PHA, we systematically derived a set of strategies for the prevention of these injuries. Gray literature from conference abstracts and presentations, public alerts, articles, and blogs, was also considered in the construction of prevention strategies. Screening of these articles was subject to the same inclusion criteria mentioned above and any pertinent information on the mechanism of injury and prevention was collected and considered. Discussion of prevention is subdivided into 4 categories: engineering and design; legislation and enforcement; education; and systems.

\section{Results}

Twenty-nine studies from 7 countries met the selection criteria. Information on head and neck injuries from the articles reviewed is summarized in Table 1. According to the data from these studies, of all age groups involved in TV-toppling incidents, toddlers most frequently suffer injuries to the head and neck, and their injuries are most likely to be severe, with an Injury Severity Score $>15 .{ }^{22}$ The case fatality rate varies widely, but almost all deaths in these series $(96 \%)$ were due to brain injuries. Murray et al. used only population-based estimates in their review of the National Electronic Injury Surveillance System, which surveys approximately 100 US hospitals. ${ }^{35}$ These investi- 


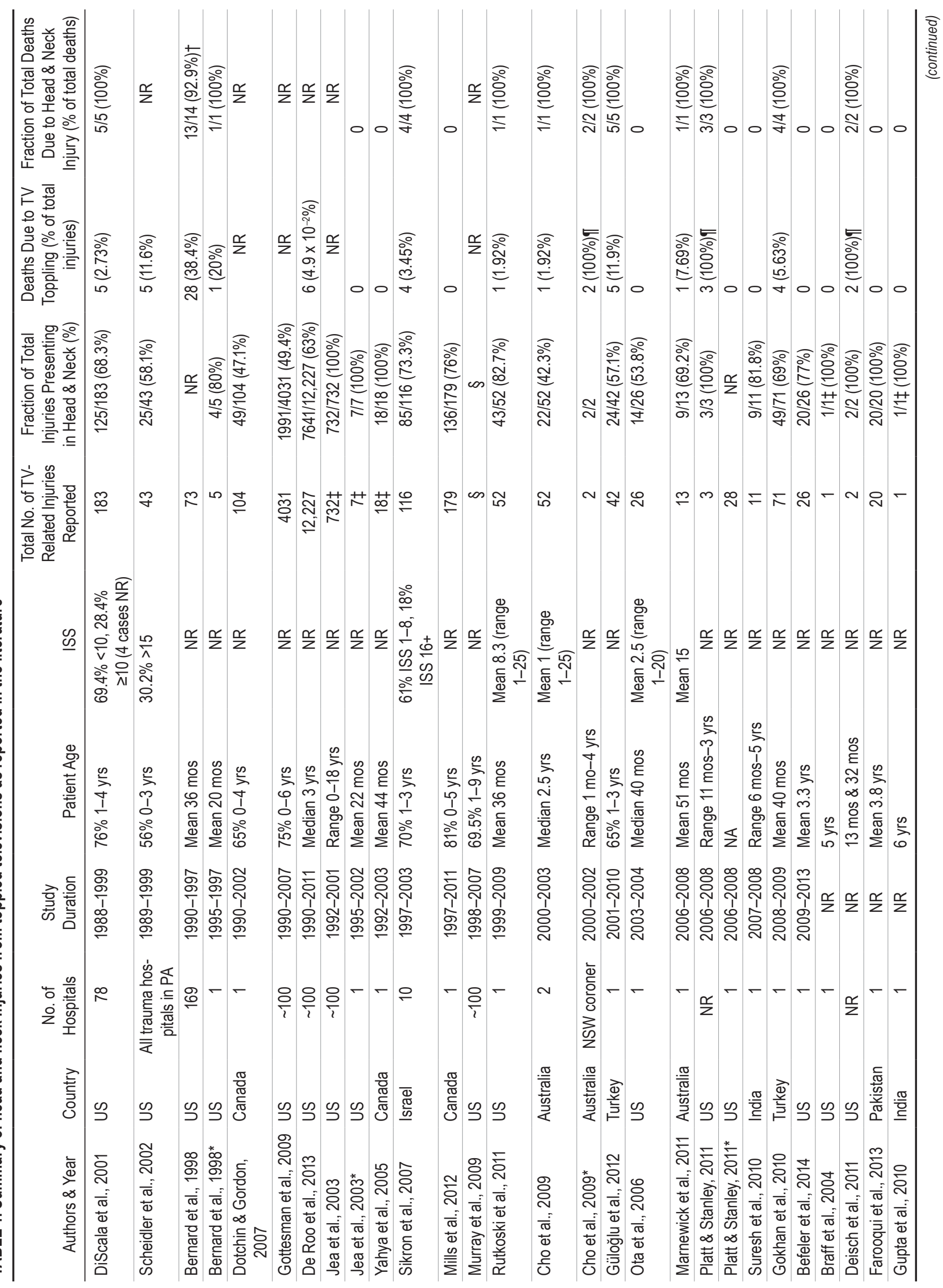




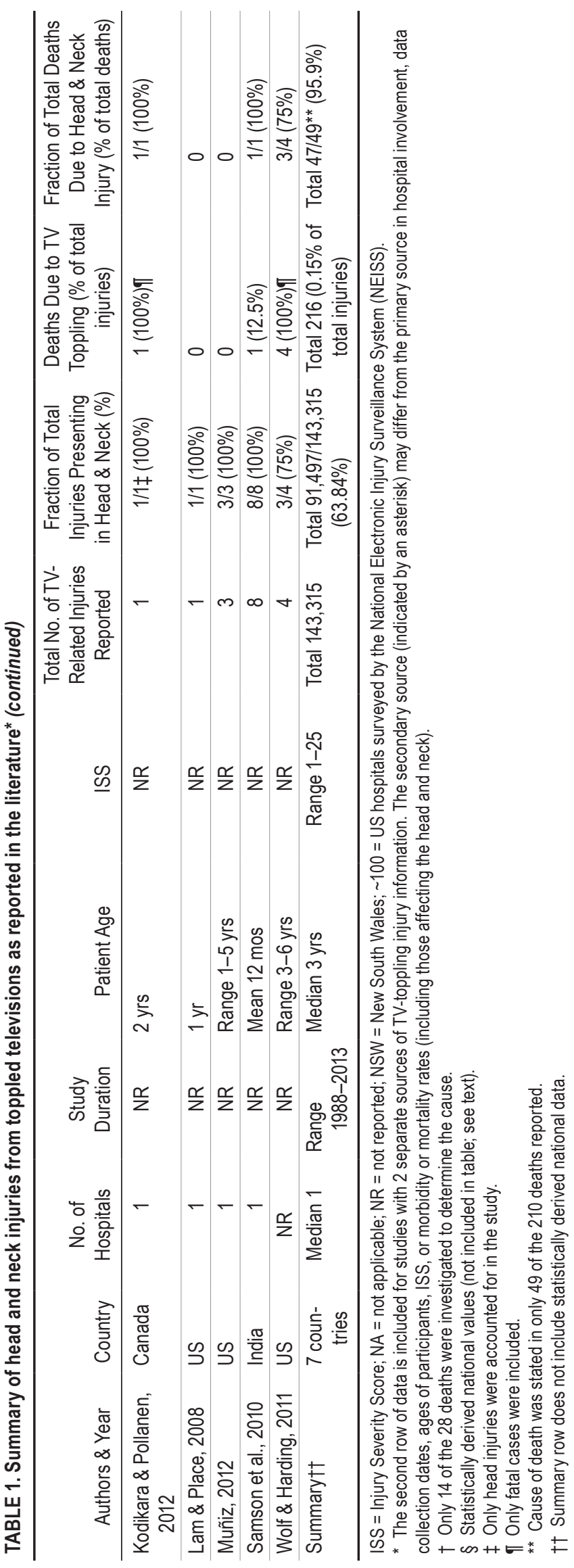

gators reported a nationally estimated 42,122 TV-toppling injuries between 1998 and 2007, 44\% of which were head injuries. National estimates of TV-toppling injuries reported by Gottesman et al. included 125,280 injuries between 1990 and 2007, and De Roo et al. reported 380,385 between 1990 and 2011.12,21

Data from multiple studies regarding the characteristics of the events that led to TV-toppling injuries are summarized in Table 2. Most (84\%) of the injuries occur at home and more than three-fourths are unwitnessed by caregivers. The TVs are most commonly large (median size 27 inches) and elevated off the ground 1-5 feet. Dressers and other furniture not designed to support televisions were commonly involved in the TV-toppling injury. The most commonly reported event leading to television toppling was a child climbing onto often unstable furniture to reach the TV or an object on top of the TV, although many studies did not report the number of incidents. There were also frequent reports of children pulling the TV onto themselves or colliding with the TV stand and thus causing the TV to topple.

A total of 160 TV-toppling cases had a specific mechanism of injury stated. Of those 160 cases, collision of the child with the stand was most common cause precipitating injury from a falling TV (Table 2). However, in the majority of studies (19/29), climbing was identified as the most significant cause of injury, but many reports did not state the number of injuries related to this mechanism. Thus, the values reported in Table 2 for events leading to TV tipover may be skewed by the few studies $(n=9)$ for which the number of cases for each mechanism of injury was reported. In some cases the events leading to injury were vaguely described (e.g., TV/stand tipping), resulting in their exclusion from analysis. Toddlers were reported to have higher rates of climbing injuries than older children ( $>4$ years old), who were more likely to collide with the TV stand. ${ }^{21,35,46}$

The wide variety of cranial pathologies caused by toppling TVs is summarized in Table 3. Superficial injuries included contusions, ear/nose/throat bleeds, abrasions, lacerations, ecchymosis, and other nonintracranial injuries. Neurological deficits included any temporary or permanent cranial nerve palsies as well as cognitive and memory deficits. These injuries can clearly be devastating or fatal.

\section{Discussion}

Haddon's Matrix (Table 4) was used to organize the factors associated with toppling injury during 3 time periods: pre-event, event, and post-event. This matrix was derived from the results of our review, and factors are discussed in order of host, agent, and environment. From these factors prevention methods were devised.

\section{Analysis of Host Factors}

The "host" in Haddon's Matrix refers to the typical victim of a particular injury. ${ }^{41}$ In the case of TV-toppling injuries, young children-specifically toddlers-are at the highest risk of injury. Factors in the host occurring before, during, and after the event contribute to the risk of injury in this group. 
TABLE 2. Factors associated with injury across the studies

\begin{tabular}{|c|c|}
\hline Factor & $\begin{array}{l}\text { Data Summary From } \\
\text { Included Studies* }\end{array}$ \\
\hline Injury at a private home & $84 \%(n=21,197)$ \\
\hline $\begin{array}{l}\text { Unwitnessed or witnessed by } \\
\text { another child (<18 yrs) }\end{array}$ & $77 \%(n=165)$ \\
\hline Height of TV stand from ground & Range $1-5 \mathrm{ft}$ \\
\hline Size of TV & Median 27 in \\
\hline $\begin{array}{l}\text { Reported events resulting in } \\
\text { tipover }\end{array}$ & $\begin{array}{l}\text { 1) Colliding with TV stand, } 75.6 \% \\
(n=121) \\
\text { 2) Climbing, } 13.1 \%(n=21) \\
\text { 3) Pulling on TV component, } 6.9 \% \\
(n=11) \\
\text { 4) Another person applying the } \\
\text { tipping force, } 4.4 \%(n=7)\end{array}$ \\
\hline
\end{tabular}

\footnotetext{
* The $n$ value represents the total number of injuries in the studies that were included. Only 160 cases had a clear mechanism of injury provided and were included in the analysis.
}

\section{Pre-Event Host Factors}

There are 3 major factors preinjury that make toddlers more susceptible to television-toppling injuries. First, young children lack the perception and awareness of many risks. ${ }^{20}$ At such a young age, toddlers' cognitive ability to recognize and avoid danger has not fully developed, leaving them much more vulnerable to injury. Studies confirm that climbing television support furniture is a common activity leading to injury. $4,35,45$ Second, uncoordinated infants and toddlers can unintentionally collide with unstable stands while playing in the vicinity of the TV, causing toppling accidents. ${ }^{22,33}$ Third, these children are exposed to the risk of television tipovers for extended periods of time every day. Not only are televisions becoming more ubiquitous, it is estimated that children 2-5 years old spend more than 32 hours per week watching TV..$^{32}$ The combination of a susceptible host with significant exposure to risk provides opportunity for preventive approaches.

\section{Event Host Factors}

At the time of the television toppling, the factor contributing to head injury is the television toppling onto an unprotected head. Because a toddler's height is shorter than most TV stands, the head is most often the first point of contact from a TV-toppling event. Protecting the head may prevent or reduce the severity of injury. However, head protection may not be the most suitable means of prevention for this injury mechanism. Although head in- juries cause the most deaths from toppling TVs, multiple injuries sustained in different body regions also increase injury severity. A study by Güloğlu et al. found that toddlers 1-3 years old were more likely to sustain injuries to multiple body regions than any other age group. ${ }^{22}$ Small children may sustain secondary brain injuries or death caused by mechanical asphyxia because of their small size in relation to the television.

\section{Post-Event Host Factors}

Small children often have a limited ability to verbalize symptoms. In the case of mild head or neck injuries the child may underplay the severity of the damage, and the injured child or other children who were present may not inform a caregiver who has not witnessed the event. This can be dangerous and allow minimal damage to progress into a more serious condition. The case report by Lam and Place shows how injuries that are seemingly minor initially can progress to severe symptoms: a 12-monthold child initially presenting with mild symptoms experienced rapid deterioration and cranial nerve deficits in a short time. ${ }^{29}$ Table 3 shows the range of head injuries that can occur and that many of those injuries require neurosurgical intervention.

\section{Analysis of Agent Factors}

The agent factors refer to energy that is transmitted to the host through a vehicle. ${ }^{41}$ The agent in this case is the television and the physical energy it transmits to the child, causing the injury. Recent changes in TV style and stability have not reflected awareness of child safety but instead have contributed to the increasing numbers of injuries caused by TVs (Table 1).

\section{Pre-Event Agent Factors}

Over the years the physical composition of the TV set has changed. The once popular bulky cathode ray tube (CRT) TV has given way to the less space-consuming flat-panel TVs (FPTVs). The base to which the TV is attached has also changed dramatically over the last couple of decades. Gone are furniture-style CRTs inserted into a rectangular wooden box with 4 short and stable legs providing 4 points of contact with the floor and a center of gravity that is largely in the center of the furniture. Newer CRT TVs have forward-shifted centers of gravity, increasing the chance of tipping, ${ }^{36}$ and also in fashion are large, poorly supported FPTVs that are frequently mounted above toddler head height.

FPTVs are thin, wide, and tall, with fairly central centers of gravity; however, even if properly secured, FPTVs

TABLE 3. Types of head injuries acquired from TV-toppling accidents

\begin{tabular}{lccc}
\hline Type of Head Injury & No. of Studies Reporting & No. of Reported Head Injuries* & \% of Reported Cases \\
\hline Superficial injuries & 17 & $14,568(n=30,447)$ & $47.8 \%$ \\
\hline Skull fractures & 19 & $136(n=360)$ & $37.7 \%$ \\
\hline Intracranial bleeding & 20 & $60(n=457)$ & $13.1 \%$ \\
\hline Neurological deficits & 8 & $50(n=249)$ & $20.1 \%$ \\
\hline
\end{tabular}

\footnotetext{
* The $n$ value represents the total number of injuries in the studies that were included.
} 
TABLE 4. Haddon's Matrix for factors associated with head injuries caused by toppled TVs

\begin{tabular}{|c|c|c|c|}
\hline \multirow[b]{2}{*}{ Time Period } & \multicolumn{3}{|c|}{ Factor } \\
\hline & Host & Agent & Environment \\
\hline Pre-Event & $\begin{array}{l}\text { Child's insufficient perception \& } \\
\text { awareness of risk. } \\
\text { Lack of coordination. } \\
\text { Increased risk exposure. }\end{array}$ & $\begin{array}{l}\text { Lack of hazard warnings on TV \& regulations } \\
\text { on securing TVs in home \& institutions. } \\
\text { Improper securing of TV. } \\
\text { Forward-shifted center of gravity. }\end{array}$ & $\begin{array}{l}\text { Caregiver lack of supervision/restriction, awareness } \\
\text { \& perception. } \\
\text { Placement of toys \& other objects desirable to } \\
\text { children on top of the TV. } \\
\text { Unstable/climbing-permissible TV support furniture. }\end{array}$ \\
\hline Event & $\begin{array}{l}\text { No protection of head. } \\
\text { Other injured body regions. } \\
\text { Mechanical asphyxia. }\end{array}$ & $\begin{array}{l}\text { Heavy weight of the TV. } \\
\text { Pointed TV edges. }\end{array}$ & Height of TV support furniture. \\
\hline Post-Event & Neglect to report "mild" injuries. & $\begin{array}{l}\text { Lack of prompt \& proper removal of TV off of } \\
\text { the child's body. } \\
\text { Lack of proper removal of penetrating TV } \\
\text { components from the child's body. }\end{array}$ & $\begin{array}{l}\text { Length of time before medical attention is sought (if } \\
\text { at all). } \\
\text { Speed \& availability of first responders. }\end{array}$ \\
\hline
\end{tabular}

have a considerable chance of toppling over. ${ }^{3,34,44}$ Very minimal force is required to tip the television forward. In one study, Dotchin and Gordon found that 31 of the 49 televisions within their Nova Scotia pediatric hospital were not secured in any way. In fact, $90 \%$ of all the TVs in this medical facility could be tipped over by children 4 years or younger. ${ }^{16}$

Consumers could be made aware of the hazard through warnings on televisions or the packaging in which they are sold, but in North America such warnings are not enforced, and the only mandatory labels on electronics (including TVs) are fire hazard warnings. ${ }^{51}$

\section{Event Agent Factors}

Several agent factors contribute to injury at the time of toppling. The sheer mass of television sets can cause a lot of damage to a child's head. TVs are now flatter and lighter than in the past, but they can still weigh more than $40 \mathrm{~kg}$, which is nearly 3 times the size of the average 3 -year-old child $(14 \mathrm{~kg}){ }^{14,33,35}$ In addition, the pointed corners of the television set can cause penetrating injuries, leading to lacerations of the face or scalp, and more severe blunt-force skull fractures. Changes to the design of TV sets can be made to help make them safer and prevent injury.

\section{Post-Event Agent Factors}

After a television has fallen onto a child, further crushing damage to the head or asphyxiation may occur if the object is not promptly removed. In older television sets, antennae are another possible source of penetrating injuries. A case report by Al-Sebeih et al. described a penetrating oral-facial injury caused by a TV antenna, which fortunately didn't cause severe damage. ${ }^{1}$ Glass TV screens can shatter, depending on the force of impact, causing lacerations and penetrating injuries.

\section{Analysis of Environmental Factors}

Environmental factors can be physical or social. These are the objects, people, and social concepts associated with the vehicle and host. In cases of TV-toppling injuries, the role of parents and caregivers who create the environment around $\mathrm{TV}$ s and must respond when injuries occur is chief among these factors.

\section{Pre-Event Environmental Factors}

Several environmental factors play key roles in TVtoppling injuries. Chief among these is the role of parents and caregivers who create the environment around TVs and who may be unaware of the high risk posed to toddlers from falling TVs. The resulting lack of safety precautions and inadequate supervision of small children are critical concerns, given that $77 \%$ of TV-toppling injuries are unwitnessed by adult caregivers.

Another risk factor is the placement of desirable objects on top of the TV, which can entice children to climb the support furniture. Stands with drawers or other components easily climbed by toddlers are more likely to lead to toppling injuries. Kodikara and Pollanen describe a case in which a 2-year-old girl attempting to climb a stand to reach the TV controls suffered a fatal toppling accident, and there are many more children who have met the same fate. ${ }^{28}$

\section{Event Environmental Factors}

The higher the stand, the more velocity the TV picks up before impact with the child's head. Thus, lower stands and those bolted to walls are safer. ${ }^{2}$ Unfortunately, far too many households have not taken these factors into consideration when making decisions about TV placement.

\section{Post-Event Environmental Factors}

Many studies show that time to medical attention after a head injury influences outcome from that head injury. ${ }^{46,55}$ Many people from low- and middle-income countries are now buying televisions, but these countries rarely have well-developed first response systems that service all areas. ${ }^{39}$ This lack of timely medical attention may lead to delays in treating primary and secondary effects of head injuries in these toddlers.

\section{Prevention}

With the factors associated with TV-toppling injuries 
clearly outlined by Haddon's Matrix, the next step in prevention, as the PHA suggests, is devising a plan of action. In this section we discuss prevention methods being used currently, ways in which these methods can be improved, and additional prevention methods not currently in practice. The topic of prevention of TV-toppling injuries in the pediatric population has been organized into 4 categories: engineering and design; legislation and enforcement; education; and systems. A list of methods of prevention is provided in Table 5.

\section{Engineering and Design}

Throughout the literature, comments about the engineering of newer generations of CRT televisions have emphasized the problem with their forward-shifted center of gravity. ${ }^{28,31,33}$ This engineering issue causes major instability in CRT TVs. The FPTVs have a more balanced center of gravity and are much lighter than CRT TVs of equivalent screen size. ${ }^{12,31}$ The thin, light design of FPTVs, however, make them more susceptible to tipping with less force applied, and much easier for children to grasp. Also, FPTVs can still weigh upward of $40 \mathrm{~kg}$, with the possibility of inflicting significant damage on children. Recent studies have reported tipover injuries caused by FPTVs leading to pediatric head injuries. ${ }^{3,12}$ Efforts should be made to design lighter TVs with evenly distributed weight and built-in anchoring systems.

Another design and engineering concern around TVtoppling events is the support furniture on which televisions are placed. The decrease in popularity of CRT TVs is not actually reducing the amount of injury. ${ }^{12}$ This may be due in part to TV owners placing older CRT TVs in less supervised rooms and on furniture that was not built to withstand the weight of the TV, thus increasing the risk of toppling events. Dressers, armoires, and bureaus are reported as the most common furniture involved in TVtoppling accidents. ${ }^{12,19,22,31,33,54}$ Although regulations are in place for testing of dressers and other household furniture, they are not tested to withstand the weight of TV sets be- cause that is not their primary use. ${ }^{2,51}$ The CPSC, along with the American Society for Testing Materials (ASTM) and the Underwriters Laboratory (UL), have regulations on the manufacturing and testing of furniture often used to support televisions. Because consumers do not always place their TV sets on the manufacturer's recommended stands, there is a greater risk of tipping. To address this issue of TV support furniture from an engineering and design point of view would be only half the battle, and so this issue is also discussed in the Legislation and Enforcement section. Ultimately, lower, wide-based stands will reduce the risk associated with toppling because a TV falling from a lower height obtains lower velocity before impact, and increased stability will decrease the risk of toppling from collisions with the stand. As climbing support furniture is reported as a major contributor to toppling events (Table 2), designing stands with fewer knobs and drawers will reduce the potential for children to climb, thus reducing toppling rates.

\section{Legislation and Enforcement}

Currently there are regulations on the stability of TV stands as well as testing of TV stability. Testing of stands is routinely done postmanufacturing. ${ }^{51}$ However, as previously mentioned, many other pieces of household furniture are used to support televisions. In light of the increased tipping accidents, ASTM revised the ASTM F2057 standards for dressers, chests, and door chests, implementing 2 new tests for stability of these furniture pieces. ${ }^{2}$ The US CPSC has regulations on the testing and safety of "Children's Products," which include television sets. ${ }^{10}$ Health Canada Consumer Product Safety and the government of the United Kingdom (UK) also have general regulations for household electronics. ${ }^{6,40,52}$ The UL is a global company contracted to test the safety of manufactured products. The UL has its own safety regulations in conjunction with regulations set by the country distributing the product. Regulations on TVs and stands are in place, but the incidence of injuries is still high. Therefore,

\section{TABLE 5. Prevention methods for pediatric TV-toppling events}

\begin{tabular}{ll}
\hline \multicolumn{1}{c}{ Factor } & \multicolumn{1}{c}{ Prevention Method } \\
\hline Host & 1. Educate children about in-home hazards including TV toppling. \\
& 2. Restricted play in rooms containing a TV. \\
\hline Vector & 3. Place safety warnings on televisions \& instructions on how to safely secure the TV. \\
& 4. Improve the design of TVs to evenly distribute the weight \& make them less easily tippable. \\
5. Place TV back away from the edge of the stand.
\end{tabular}


improvements in these regulations and better enforcement is needed.

There are areas in which legislation on TVs and TV stands is lacking and improvements could potentially serve to reduce toppling accidents. Current legislation regarding warnings placed on TVs focuses on fire hazard labels. ${ }^{6,51}$ Implementing legislation requiring that mandatory warning labels for tipping be placed on televisions could be beneficial. Mandatory provision of proper anchoring brackets and TV straps at the point of sale should also be implemented. Along with anchoring devices there should be clear instructions on how to properly anchor TVs and stands. Another option is to sell TV-specific stands in conjunction with the television. This would increase the chances of televisions being placed on the proper support furniture; however, accomplishing this without other consumer costs would be important.

\section{Education}

Improved public education is important for the prevention of TV toppling. Parents, caregivers, teachers, and medical professionals should be educated on the strategies that can be used to reduce the risk of television injuries. These strategies include increasing and improving supervision of children within the home, restricting play around TV sets, anchoring of TVs and TV stands, never placing televisions on dressers and other household furniture, selecting stands that are short with wide bases, placing TVs as far back from the edge of the stand as possible, and never placing desirable objects for children on top of the TV. Once a toppling event has occurred, an injured child's outcome can be greatly improved by parents and caregivers previously educated to speedily remove a fallen TV from the child's body, to administer first aid such as cardiopulmonary resuscitation tactics, not to remove any deep penetrating objects, and to seek medical attention immediately.

Efforts to educate the general public through national campaigns can be improved. The US CPSC and Health Canada issue annual warnings. The UK's Home Accident Surveillance System (HASS; http://www.hassandlass.org. uk) was terminated in 2002, but this system previously reported TV toppling as a large contributor to pediatric head injury. ${ }^{40}$ The Royal Society for Prevention of Accidents in the UK also warns the public about TV-toppling accidents.

Increasing awareness and prevention are occurring but are failing to reach a large audience. As Ota et al. reported, $85 \%$ of caregivers were unaware of TV toppling as a potential hazard. ${ }^{36}$ Placing warnings on more high-traffic websites should increase the number of people exposed to the warnings. Another option is to distribute educational pamphlets at the point of sale. Also, simply placing labels warning of toppling on TV sets increases awareness, as addressed in the Legislation and Enforcement section.

\section{Systems-First Responders}

Although TV-toppling injuries may not be severe in all cases (Tables 1 and 4), seeking medical care for head injuries is important. Even with seemingly mild injuries, progression into more severe conditions may be avoided if medical care is sought. ${ }^{29,46,55}$ Thus, caregivers should take an injured child to the nearest emergency department or call for emergency assistance. Cases that need emergency medical attention would benefit from fast, organized, emergency response systems. However, in many developing countries, and even in rural areas of developed countries, emergency first response is nonexistent or is not timely. ${ }^{39}$ Adding to the issue is the affordability of CRT TVs in developing countries. ${ }^{17,47}$ Families of lower socioeconomic status in these countries are more likely to buy unstable heavy TVs, and in the unfortunate event of a toppling accident they may not have the benefits of an emergency medical care system. Although these system factors have larger implications than timely care of TV-toppling injuries, they are worth mentioning in the prevention of this mechanism of injury.

\section{Limitations of the Study}

Our review of the literature was systematic and thorough; however, all of the papers that we identified were case series or case reports. The papers reviewed provided little focus on the prevention of head injuries. The US CPSC and Health Canada warnings have never been evaluated for their impact, and it is unclear how many consumers actually read these websites. Properly designed studies from different jurisdictions that address the effectiveness of the types of interventions that we have suggested are required.

\section{Conclusions}

Television-toppling injuries can be easily prevented; however, the rates of injury do not reflect a sufficient level of awareness, nor do they reflect an acceptable effort from an injury prevention perspective. Amendments to current legislation and implementation of additional regulations are suggested to reduce injury rates. Improvements in the design of television sets and stands as well as better tactics to educate the public are recommended. Also, the effort to prevent these injuries would benefit from prospective studies to better understand the injury mechanism. Future implementation of the aforementioned prevention recommendations would go a long way toward reducing head and neck injuries from TV-toppling events.

\section{References}

1. Al-Sebeih K, Karagiozov K, Jafar A: Penetrating craniofacial injury in a pediatric patient. Craniofacial Surgery 13:303307,2002

2. American Society for the Testing of Materials: Standard Safety Specification for Chests, Door Chests, and Dressers: F2057-09b. West Conshohocken, PA: ASTM, 2009

3. Befeler AR, Daniels DJ, Helms SA, Klimo P Jr, Boop F: Head injuries following television-related accidents in the pediatric population. J Neurosurg Pediatr 14:414-417, 2014

4. Bernard PA, Johnston C, Curtis SE, King WD: Toppled television sets cause significant pediatric morbidity and mortality. Pediatrics 102:E32, 1998

5. Braff SB, Khoshyomn S, D’Angelo WF, Tranmer BI, Wilson JT: Traumatic transverse sinus laceration. Pediatr Neurosurg 40:143-144, 2004

6. Canada Consumer Product Safety Act, S.C. 2010, c. 21

7. Cho JH, Adams S, Holland AJ: Furniture injuries in children. J Paediatr Child Health 45:505-508, 2009 
8. Consumer Product Safety Commission: CPSC releases the top five hidden home hazards. August 1, 2007. (http://www. cpsc.gov/en/newsroom/news-releases/2007/1cpsc-releasesthe-top-five-hidden-home-hazards-safety-agency-placespopular-magnetic-toys-on-the-list-of-deadly-dangers/) [Accessed June 12, 2015]

9. Consumer Product Safety Commission: CPSC warns about TV, large furniture tip-over dangers. September 12, 2006. (http://www.cpsc.gov/en/Newsroom/News-Releases/2006/ CPSC-Warns-about-TV-Large-Furniture-Tip-OverDangersMore-than-100-Deaths-Reported-Since-2000-MostInvolve-Young-Children/) [Accessed June 12, 2015]

10. Consumer Product Safety Commission: Testing and labeling pertaining to product certification regarding representative samples for periodic testing of children's products. Fed Regist 77:72205-72219, 2012

11. Consumer Product Safety Commission: The tipping point: CPSC urges parents to inspect and secure TVs, furniture, and appliances to prevent tip-over deaths and injuries. September 22, 2009. (http://www.cpsc.gov/en/Newsroom/NewsReleases/2009/The-Tipping-Point-CPSC-Urges-Parentsto-Inspect-and-Secure-TVs-Furniture-and-Appliances-toPrevent-Tip-Over-Deaths-and-Injuries/) [Accessed June 12, 2015]

12. De Roo AC, Chounthirath T, Smith GA: Television-related injuries to children in the United States, 1990-2011.

Pediatrics 132:267-274, 2013

13. Deisch J, Quinton R, Gruszecki AC: Craniocerebral trauma inflicted by television falls. J Forensic Sci 56:1049-1053, 2011

14. Disabled World: Average height to weight chart - babies to teenagers. (http://www.disabled-world.com/artman/publish/ height-weight-teens.shtml) [Accessed June 15, 2015]

15. DiScala C, Barthel M, Sege R: Outcomes from television sets toppling onto toddlers. Arch Pediatr Adolesc Med 155:145148,2001

16. Dotchin SA, Gordon KE: The terrible truth about toppling televisions. Paediatr Child Health (Oxford) 12:221-224, 2007

17. Farooqui M, Quadri S, Zafar A, Tahir M, Javed G: Outcome and patterns of traumatic brain injury in pediatric population of a third world country secondary to TV-trolley tip over. Neurology 80 (Meeting Abstracts 1):P06.237, 2013 (Abstract)

18. Gipson K, Suchy A: Instability of Televisions, Furniture, and Appliances: Estimated Injuries and Reported Fatalities, 2010 Report. Bethesda, MD: Consumer Product Safety Commission, 2011 (http://www.cpsc.gov/ pagefiles/108988/tipover.pdf ) [Accessed June 12, 2015]

19. Gipson K, Suchy A: Instability of Televisions, Furniture, and Appliances: Estimated Injuries and Reported Fatalities, 2011 Report. Bethesda, MD: Consumer Products and Safety Commission, 2011 (http://www.cpsc.gov/ pagefiles/108985/tipover2011.pdf ) [Accessed June 12, 2015]

20. Gokhan S, Kose O, Ozhasenekler A, Orak M, Ustundag M, Guloglu C: Mortality and morbidity in children caused by falling televisions: a retrospective analysis of 71 cases. Int $\mathbf{J}$ Emerg Med 3:305-308, 2010

21. Gottesman BL, McKenzie LB, Conner KA, Smith GA: Injuries From furniture tip-overs among children and adolescents in the United States, 1990-2007. Clin Pediatr (Phila) 48:851-858, 2009

22. Güloğlu R, Sarıcı IS, Bademler S, Emirikçi S, Işsever H, Yanar H, et al: Falling television related child injuries in Turkey: 10-year experience. Ulus Travma Acil Cerrahi Derg 18:61-64, 2012

23. Gupta S, Bundela Y, Kumar V, Gupta V, Dua S, Singh AK: Diastasis of the coronal suture with a difference. $\mathbf{J}$ Neurosurg Pediatr 6:511, 2010

24. Health Canada: Danger! Furniture and televisions can tip over onto children - fact sheet. (http://publications.gc.ca/ pub?id=9.671001\&sl=0)[Accessed June 15, 2015]

25. Health Canada: Health Canada reminds Canadians of the dangers related to furniture, television and appliance tip-overs. HealthyCanadians. February 4, 2010. (http:// healthycanadians.gc.ca/recall-alert-rappel-avis/hcsc/2010/13454a-eng.php?_ga=1.8281840.319239643.14341170 07) [Accessed June 12, 2015]

26. Howard R, Houghton C: Improving parental first-aid practices. Emerg Nurse 20:14-19, 2012

27. Jea A, Ragheb J, Morrison G: Television tipovers as a significant source of pediatric head injury. Pediatr Neurosurg 38:191-194, 2003

28. Kodikara S, Pollanen M: Fatal pediatric head injury due to toppled television: does the injury pattern overlap with abusive head trauma? Leg Med (Tokyo) 14:197-200, 2012

29. Lam SH, Place R: Subtle presentation of isolated brainstem injury in a child with minor head injury. Ann Emerg Med 51:375-377, 2008

30. Lett R, Kobusingye O, Sethi D: A unified framework for injury control: the public health approach and Haddon's Matrix combined. Inj Control Saf Promot 9:199-205, 2002

31. Marnewick J, Dansey R, Morreau P, Hamill J: Television tip-overs: the Starship Children's Hospital experience and literature review. Injury 42:534-538, 2011

32. McDonough P: TV viewing among kids at an eight-year high. Nielsen Wire. October 26, 2009. (http://www.nielsen.com/ us/en/insights/news/2009/tv-viewing-among-kids-at-an-eightyear-high.html) [Accessed June 12, 2015]

33. Mills J, Grushka J, Butterworth S: Television-related injuries in children - the British Columbia experience. J Pediatr Surg 47:991-995, 2012

34. Muñiz AE: Craniofacial injuries from television tip-over. Pediatr Emerg Care 28:52-54, 2012

35. Murray KJ, Griffin R, Rue LW III, McGwin G Jr: Recent trends in television tip over-related injuries among children aged 0-9 years. Inj Prev 15:240-243, 2009

36. Ota FS, Maxson RT, Okada PJ: Childhood injuries caused by falling televisions. Acad Emerg Med 13:700-703, 2006

37. Pereira J: 15 accidents that can kill kids. ParentsCanada. April 27, 2007. (http://www.parentscanada.com/baby/15accidents-that-can-kill-kids) [Accessed June 12, 2015]

38. Platt MS, Stanley C: TV tip-over morbidity and mortality in children. J Forensic Sci 56:1364-1367, 2011

39. Razzak JA, Kellermann AL: Emergency medical care in developing countries: is it worthwhile? Bull World Health Organ 80:900-905, 2002

40. Royal Society for the Prevention of Accidents: Accident statistics: 2002-2002 data. Home \& Leisure Accident Surveillance System. (http://www.hassandlass.org.uk/ reports/2002data.pdf) [Accessed June 12, 2015]

41. Runyan CW: Using the Haddon matrix: introducing the third dimension. Inj Prev 4:302-307, 1998

42. Rutkoski JD, Sippey M, Gaines BA: Traumatic television tip-overs in the pediatric patient population. J Surg Res 166:199-204, 2011

43. Samson SKG, Nair PR, Baldia M, Joseph M: Television tipover head injuries in children. Neurol India 58:752-755, 2010

44. Sanus: Child injuries from TV tip-overs increasing in the US. PR Newswire. July 25, 2013. (http://www.prnewswire.com/ news-releases/child-injuries-from-tv-tip-overs-increasing-inthe-us-216907411.html) [Accessed June 12, 2015]

45. Scheidler MG, Shultz BL, Schall L, Vyas A, Barksdale EM Jr: Falling televisions: The hidden danger for children. J Pediatr Surg 37:572-575, 2002

46. Schutzman SA, Greenes DS: Pediatric minor head trauma. Ann Emerg Med 37:65-74, 2001

47. Sikron F, Glasser S, Peleg K: Children injured following 
TV tipovers in Israel, 1997-2003. Child Care Health Dev 33:45-51, 2007

48. Singer AJ, Gulla J, Thode HC Jr, Cronin KA: Pediatric first aid knowledge among parents. Pediatr Emerg Care 20:808811,2004

49. Suresh N, Harini G, Radhika R, Chidambaram B: Head injuries in children resulting from the fall of television. Indian J Pediatr 77:459-460, 2010

50. Tekin D, Suskan E: What do parents know? A survey on pediatric first aid knowledge of 631 parents in Turkey. Turkiye Klinikleri J Med Sci 30:1999-2003

51. Underwriters Laboratories: UL 6500/60065 Practical Application Guidelines. (http://industries.ul.com/consumertechnology/consumer-electronics) [Accessed June 12, 2015]

52. United Kingdom Parliament: General Product Safety Regulations, 2005 No. 1803

53. Wolf BC, Harding BE: Household furniture tip-over deaths of young children. J Forensic Sci 56:918-921, 2011

54. Yahya RR, Dirks P, Humphreys R, Rutka JT, Taylor M, Drake JM: Children and television tipovers: a significant and preventable cause of long-term neurological deficits. J Neurosurg 103 (3 Suppl):219-222, 2005

55. Zabek M, Zaczyński A: The golden hour and the dull reality.
Analysis of traumatic brain injury management in prehospital and emergency care. Neurol Neurochir Pol 41:2227,2007

\section{Disclosure}

The authors report no conflict of interest concerning the materials or methods used in this study or the findings specified in this paper.

\section{Author Contributions}

Conception and design: both authors. Acquisition of data: Parker. Analysis and interpretation of data: Parker. Drafting the article: both authors. Critically revising the article: both authors. Reviewed submitted version of manuscript: both authors. Approved the final version of the manuscript on behalf of both authors: Parker. Study supervision: Cusimano.

\section{Correspondence}

Nadine Parker, Injury Prevention Research Office, 30 Bond St., Toronto, ON M5B 1W8, Canada. email: 13np16@queensu.ca. 